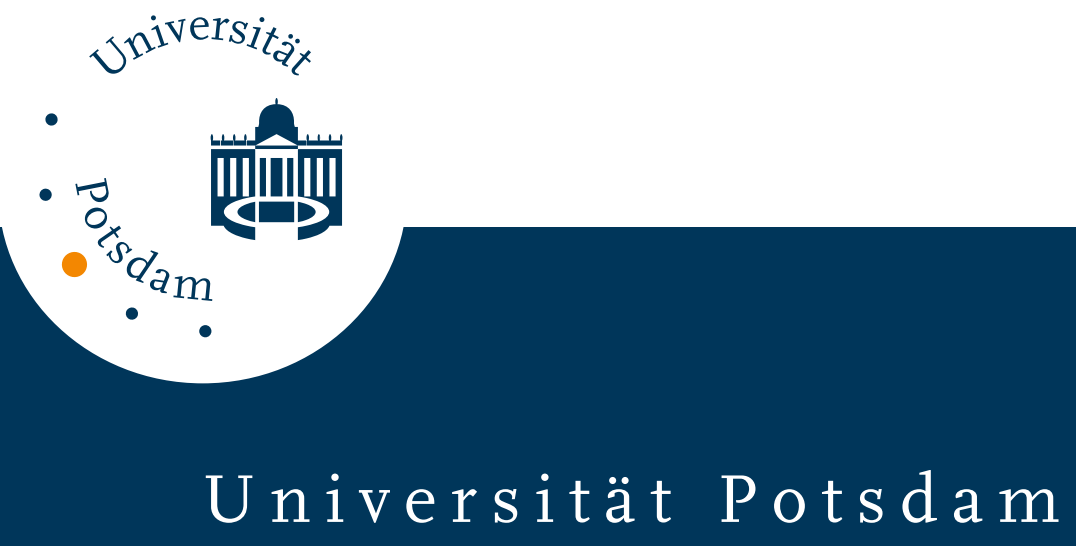

Reinhold Kliegl, Douglas Bates

\title{
International Collaboration in Psychology is on the Rise
}

first published in:

Scientometrics. - ISSN 0138-9130. - 87 (2011), 1, S. 149-158

Postprint published at the Institutional Repository of the Potsdam University: In: Postprints der Universität Potsdam

Humanwissenschaftliche Reihe ; 244

http://opus.kobv.de/ubp/volltexte/2011/5704/

http://nbn-resolving.de/urn:nbn:de:kobv:517-opus-57045

Postprints der Universität Potsdam

Humanwissenschaftliche Reihe ; 244 
This is a preprint of an article whose final and definitive form was published in

\title{
Scientometrics
}

An International Journal for all Quantitative Aspects of the Science of Science, Communication in Science and Science Policy ISSN 0138-9130 Volume 87 Number 1 Pages 149-158

Link: DOI 10.1007/s11192-010-0299-0

Copyright 2011 Springer

\section{International Collaboration in Psychology is on the Rise}

\author{
Reinhold Kliegl \\ Dept. of Psychology, University of Potsdam, Potsdam, Germany \\ $\&$ \\ Douglas Bates \\ Dept. of Statistics, University of Wisconsin, Madison, USA
}

Running head: International collaboration in psychological science

Corresponding author:

Reinhold Kliegl

Department of Psychology

University of Potsdam

Postfach 601553

14415 Potsdam, Germany

Tel: +49-331-977 2346, Fax: +49-331-977-2793 


\begin{abstract}
There has been a substantial increase in the percentage for publications with co-authors located in departments from different countries in 12 major journals of psychology. The results are evidence for a remarkable internationalization of psychological research, starting in the mid 1970s and increasing in rate at the beginning of the 1990s. This growth occurs against a constant number of articles with authors from the same country; it is not due to a concomitant increase in the number of co-authors per article. Thus, international collaboration in psychology is obviously on the rise.
\end{abstract}




\section{International Collaboration in Psychological Science is on the Rise}

The world is growing together and scientific collaboration is one very encouraging piece of evidence for it. How is this trend reflected in scientific publications? Comprehensive analyses of bibliometric ISI records, distinguishing between international and national articles, have been available at least since the year 2000 (National Science Board, 2000, chapter $6 ; 2008$, chapter 5, table 5-37). In 2005, 27\% of journal articles with a US author involved at least one co-author from a different country, up from 17\% in 1995; the highest rate of international articles (58\%) was determined for astronomy (1995: 42\%); psychology is listed with $7.7 \%$ in 1995 and $13.6 \%$ in 2005 . In a study recently commissioned for the UK Office of Science and Innovation, Adams, Gurney, and Marshall (2007) determined the number of collaborative articles between nine countries (UK, USA, Canada, France, Germany, India, Japan, Australia, China) for seven fields of research (clinical, health, biological sciences, environment, mathematics, physical sciences, and engineering). Growth ratios for the two periods 1996-2000 and 2001-2005 ranged between 1.16 and 2.15.

A remarkable linear increase from 3 percent in 1990 (when this journal was founded) to 31 percent in 2008 was reported for Psychological Science (Kliegl, 2008, Figure 2). There are three questions to be followed up here: First, how does this trend look for journals with a longer history than Psychological Science? Second, how representative is this trend across journals devoted to basic research in psychology? And, third, does the increase in percentage of internationally co-authored articles occur against growth or decline in the absolute number of "national" articles (i.e., articles with all authors from the same country)? In addition, we show that the results are not simply due to a concomitant increase in the number of authors per article or due to differences in developmental trends between journals. 


\section{Method}

Analyses are based on 26,722 articles and reviews published from 1975 to 2007 in 12 psychology journals. Our selection represents basic experimental psychological research with journals that have enjoyed a very high reputation in the various subfields of this discipline. Most of them are published by the American Psychological Association (APA), but we also included the major journals from the Association for Psychological Science (APS), the Psychonomic Society (PS), the Society for Psychophysiological Research (SPR); one of them belongs to a commercial publishing house. Specifically, the journals are Biological Psychology [Elsevier], Developmental Psychology, Journal of Experimental Psychology: General, Journal of Experimental Psychology: Human Perception and Performance, Journal of Experimental Psychology: Learning, Memory, and Cognition, Journal of Personality and Social Psychology, Psychology and Aging, Psychological Bulletin, Psychological Review [all APA], Psychological Science [APS], Psychonomic Bulletin \& Review [PS], and Psychophysiology [SPR]). With the exception of the somewhat more recently started premier APS and PS journals, the other journals have held a high reputation for at least 20 years. Information was retrieved from the ISI Web of Science (Thomson Scientific) during the second quarter of 2008 .

We categorized records by journal name, year of publication, and whether the article was by institutional authors from at least two countries (international) or by an institutional author or several authors from the same country (national). Authors may, of course, be of different nationalities than the institutes they list as their affiliations. A few single-author articles (85) listed affiliations with institutions in different countries; they were classified as national articles. Graphics were produced with the lattice package (Sarkar, 2008) and inferential statistics were based on linear mixed models (LMMs) using the lmer program 
(lme4 package; Bates \& Maechler, 2010). Both packages are part of the R environment for statistical computing and graphics (R Development Core Team, 2010).

\section{Results}

The answers to the first two questions about the long-term historical trend for percentages of international articles and its consistency across different journals are displayed in Figures 1 and 2. The percentage of international articles grows at constant rate of $7.4 \%$ as estimated from a regression of log percentage on year with year centered at 1990. This amounts to a linear increase of about 1/3 \% per year from 1975 to 1990 and $1 \%$ per year since then. The panels of Figure 2 display this trend separately for the 12 journals, including also a loess-based smooth within each panel. Journals published since at least 1975 tend to show the curvilinear or bilinear trend of Figure 1. Descriptive statistics about the database (i.e., total number of articles/reviews, overall percentage and percentage of international articles in last three years) is provided in the left part of Table 1.

\section{Insert Figure 1, Figure 2, and Table 1 about here}

The right part of Table 1 displays "estimates" of the percentage of international articles in the year 1990 as well as "estimates" of the linear slopes from 1975 to 1990 and from 1990 to 2007 for each journal. Strictly speaking these are the conditional modes evaluated at the estimated random effects of a linear-mixed effect model specifying the 12 journals as a random factor (yielding an estimate of the variance of the percentage of international journals in 1990) and estimating the variances of journal slopes prior to and after 1990. Note that for journals starting after 1990, the fixed effect slope for the pre-1990 period is returned as the best estimate. The increase in international articles is very pervasive.

Primarily for ease of interpretation, we fitted two linear slopes to percentages of international articles to document the accelerated growth of articles of this type. Is this growth due to an increase in the total number of publications or due to a decrease in the 
number of national articles (or both)? Figure 3 displays the log number of publications for national and international articles for the years 1975 to 2007, with articles pooled across journals. Growth has been much stronger for international than for national articles. Thus, the historical increase in international articles did not occur at the "cost" of a reduction of national ones.

\section{Insert Figure 3 about here}

As shown in Figure 4, the lines in Figure 3 smooth across substantial differences in developmental trends between the 12 journals. For most journals, the number of national articles (the top line in each panel) has not changed much across the last 33 years, but there are exceptions: Journals that started in the last 20 years such as Psychological Science or Psychonomic Bulletin \& Review show growth; some of the others, such the Journal of Personality and Social Psychology and Psychological Bulletin, evince a decrease in number of national articles.

For statistical inference, we regressed the log numbers of articles on type of article (national, coded as 0 , and international, coded as 1), linear and quadratic trends of time (centered at 1990), and the interactions between these trends and type of journal. Journal was specified as a random factor. We also estimated the variability between journals for all fixed effects as well as the correlations between them. Estimates are reported in Table 2. The first three columns describe the regression line for the national articles; the coefficients for international articles reflect the difference to the corresponding coefficients for national articles, that is the coefficients for international articles can be computed by adding the corresponding coefficients. The results are straightforward. Overall (after statistically controlling for between journal differences), there is no significant change in log number of national articles across the 33 years--neither in the linear nor in the quadratic component $(t-$ 
values $<1.0$ ), but there is a highly significant difference between the linear trends for national and international articles $(t=12.98)$.

The overall pattern is accompanied by reliable variance between journals for all estimated coefficients (see Random Effects in Table 2). From these estimates, we can compute the conditional modes of the random effects, Pinheiro \& Bates, 2000) for each of the 12 journals. These coefficients are also listed in Table 2; they basically mirror the differences between the journal curves shown in Figure 4.

\section{Insert Figure 4 and Table 2 about here}

There has been an increase in the total number of articles in basic psychological research. International articles have profited from this development. There is, however, one potential confound: Historically, there has also been a change in the mean number of authors. Already Smith (1958) reported an increasing trend in the percentage of papers by two and three authors, a decreasing trend in the percentage of papers by one author, and a trend toward an increasing mean number of authors for articles published in the American Psychologist in the years 1946-1958. Single-author papers are national articles, but the increase in number of international articles could be due to a correlated increase in the number of authors per article. Possibly, the increase in international articles rides on an overproportional increase in the number of collaborating authors - even if there was only a remote chance that this should be the case. Indeed, the data clearly refuted this hypothesis. As shown in Figure 5, larger growth rates were observed for international than national articles, irrespective of whether they were written by 2,3 , or 4 or more authors. Thus, the increase in international collaboration remains even after stratification by the number of authors. Interestingly, the log number of single-author papers exhibits accelerated decline over the years.

Insert Figure 5 about here 


\section{Discussion}

The number of articles co-authored by psychological scientists from different countries is increasing. This increase of international publications is absorbed by new journals and expansions of old journals rather than by reduction of the number of national publications. Overall the development of the percentage of international articles appears to be well characterized by exponential growth with a constant rate of about $7 \%$ per year; linear increments were around $1 / 3 \%$ before 1990 and have been above $1 \%$ during the last 17 years.

The smooth overall growth is complemented by varied growth and decline curves seen for the national-article lines at the level of journals (i.e., Figure 4). Thus, in which journals the growing number of articles will be published depends on poorly understood subdisciplinary (perhaps also interdisciplinary) dynamics. For example, on the one hand, the decrease in number of articles appearing in the APA's Psychological Bulletin is largely due to moving methodological contributions from this journal to APA's Psychological Methods, newly founded in 1996. Of course, reputation and fashion will also exert their force at this levels and there may also be some, we suspect a very small, contribution from increasing demand for journal space from international submissions. On the other hand, the increases for Psychological Science and Psychonomic Bulletin \& Review are what one would expect from startup journals. These kinds of wheeling and dealing reshuffle publications between journals but apparently they do not much affect the smooth general growth.

Interestingly, as far as international articles are concerned, all journals show growth, but growth rates differ significantly. In general, the growth for international articles appears to be somewhat decoupled from the dynamics visible for national articles, presumably because linear growth was quite subtle for a long time (i.e., below $0.3 \%$ per year) and did not represent a strong competition for journal space nor was it a political issue. For example, 
there never was an official APA policy to increase or restrict the number of international articles (Rayner, personal communication, June 18, 2008).

International collaboration is definitely on the rise across all of science. The growth is likely to be linked to cultural innovations such as the introduction of web and email correspondence in the 1980s. It is the result of a not so frequent convergence of interest of national policies and individual scientists. Government policies and individual competition for funds are both driven in part by the need for increasing specialization in various subfields of research. As a result, student and scientist exchange programs are actively advertised and implemented. Review panels of Deutsche Forschungsgemeinschaft, for example, often use evidence of international collaboration as one positive indicator in grant evaluations. As a consequence, there has been an increase in the availability of international fellowships. Of course, student-mentor relations typically extend beyond the time of supervision; students will keep publishing with their advisors after returning home. The resulting facilitation of exchanges of doctoral and postdoctoral students as well as funding of visiting or guest professor positions has certainly contributed to the sustained growth in international publications.

In addition to the facilitation of international collaboration by government and foundation policies, there has also been a strong increase in international academic mobility over the last years, forced in part by a lack of adequate positions in some countries (for example Germany) and met by an expansion of the tertiary educational sector in others (for example the United Kingdom). This "brain drain"--as it is referred to--of usually aboveaverage productive colleagues from one country to another does not sever established collaborations with research partners in the home country and contribute to the pool of international articles. 
Of course, the positive connotations associated with international collaboration (i.e., that it is generally perceived to be good that people of different countries collaborate) should not be taken prima facie as hard evidence that research results published in international articles are in any way superior to those in national ones (see Katz \& Martin, 1997, for a discussion of the various facets of collaboration). Adams et al. (2007), with due precaution, report that international articles achieve a higher citation impact (corrected for age of publication) than UK publications. Fewer international than UK articles remain uncited and the entire distribution of citation impact is generally shifted further towards the high end for international than national articles. They conclude that their "data confirm the substantial advantage gained through international collaboration" (p. 21). Of course, such a result does not inform whether international articles achieve higher impact because of quality of research or because of larger social networks associated with them, to name two possible, but very different reasons.

The explanations for the rise in international collaboration sketched in the Discussion are not exclusive of each other and there are probably other sources. At this point we present them as conjectures, but they could stimulate quantitative research into the history, sociology, and social psychology of psychological research. Irrespective of the relative weights of mechanisms responsible for this pervasive change in publication patterns, international collaboration in psychology in particular and in science in general is obviously on a generally much welcome rise. 


\section{References}

Adam, J., Gurney, K., \& Marshall, S. (2007). Patterns of international collaboration for the UK and leading partners: A report commissioned by the UK Office of Science and Innovation. Leeds, UK: Evidence Lmt..

Bates, D.M., \& Maechler, M., (2010). lme4: Linear mixed-effect models using S4 classes. R package version 0.999375-34 [Software]. Vienna, Austria: R Foundation for Statistical Computing.

Katz, J.S., \& Martin, B.R. (1997). What is research collaboration. Research Policy, 26, 1-18.

Kliegl, R. (2008). Publication statistics show collaboration, not competition. APS Observer, 21.

National Science Board (2000). Science and Engineering Indicators 2000. Arlington, VA: National Science Foundation.

National Science Board (2008). Science and Engineering Indicators 2008. Arlington, VA: National Science Foundation.

Pinheiro, J., \& Bates, D. (2000). Mixed-effects models in S and S-Plus. New York: Springer.

R Development Core Team (2010). R: A language and environment for statistical computing. (version 2.11.1) R Foundation for Statistical Computing, Vienna, Austria. ISBN 3-900051-070, URL http://www.R-project.org.

Sarkar, D. (2008). Lattice: Multivariate data visualization with R. New York:Springer.

Smith, M. (1958). The trend toward multiple authorship in psychology. American Psychologist, 13, 596-599. 


\section{AUTHOR NOTE}

We thank Bernhard Angele and Steffen Kleinschmidt for help with assembling the data base and Barbara Krahé . Keith Rayner, and Eike Richter for helpful comments.

Address for correspondence: Reinhold Kliegl, Department of Psychology, University of Potsdam, Karl-Liebknecht-Str. 24-25, 14476 Potsdam, Germany. Email: kliegl@uni-potsdam.de 
Table 1. Descriptive statistics and best linear unbiased estimates (BLUPs) for percentages of international articles for 11 psychology journals (see Figure 2).

\begin{tabular}{|c|c|c|c|c|c|c|c|}
\hline \multirow[t]{3}{*}{ Journal } & \multirow{3}{*}{$\begin{array}{l}\text { First } \\
\text { year }\end{array}$} & \multirow{3}{*}{$\begin{array}{c}\mathrm{N} \\
\text { articles }\end{array}$} & \multirow{3}{*}{$\begin{array}{c}\text { Intern. } \\
\text { articles } \\
\text { (overall) } \\
\%\end{array}$} & \multirow{3}{*}{$\begin{array}{c}\text { Intern. } \\
\text { articles } \\
\text { ('05-'07) } \\
\%\end{array}$} & \multicolumn{3}{|c|}{$\begin{array}{l}\text { LMM estimates (\%) } \\
\text { (conditional modes) }\end{array}$} \\
\hline & & & & & mean & slope & slope \\
\hline & & & & & 1990 & '75-690 & '90-'07 \\
\hline Psychophysiology & 1975 & 2596 & 15 & 32 & 10.91 & 0.52 & 1.13 \\
\hline Biol Psychol & 1975 & 1347 & 11 & 19 & 6.02 & 0.10 & 0.83 \\
\hline Dev Psychol & 1975 & 3177 & 10 & 17 & 7.36 & 0.40 & 0.83 \\
\hline Psychol Aging & 1987 & 1306 & 12 & 19 & 5.13 & 0.36 & 0.95 \\
\hline J Pers Soc Psychol & 1975 & 6279 & 10 & 30 & 6.61 & 0.33 & 1.26 \\
\hline J Exp Psychol Human & 1975 & 2592 & 17 & 32 & 10.73 & 0.58 & 1.25 \\
\hline J Exp Psychol Learn & 1975 & 2706 & 11 & 25 & 6.87 & 0.28 & 1.00 \\
\hline J Exp Psychol Gen & 1975 & 883 & 14 & 32 & 8.84 & 0.41 & 1.16 \\
\hline Psychol Bull & 1975 & 1964 & 8 & 25 & 5.67 & 0.20 & 0.92 \\
\hline Psychol Rev & 1975 & 946 & 16 & 33 & 9.85 & 0.33 & 1.23 \\
\hline Psychon B Rev & 1994 & 1269 & 18 & 23 & 4.87 & $0.35 *$ & 1.02 \\
\hline Psychol Sci & 1990 & 1707 & 18 & 23 & 6.44 & $0.35^{*}$ & 1.07 \\
\hline
\end{tabular}

Note. $\mathrm{N}$ of percentages for linear mixed-effects model: 350; $\log$ Lik $=-1032$; deviance $=2058$, REML deviance $=2064$. Fixed effects: mean for $1990=7.4 \%(S E=0.8, t=8.9)$; slope for '75'90 $=0.35(S E=0.09, t=3.9)$; slope for '90-'07 = $1.06(S E=0.07, t=14.1)$. Random effects: $\operatorname{sd}(1990)=2.40 ; \operatorname{sd}\left(\right.$ slope $\left.{ }^{\prime 75}{ }^{`} 90\right)=0.19 ; \operatorname{sd}($ slope '90-'07)=0.19; $\operatorname{sd}($ resid $)=4.29$. *: pre-1990 slope estimates based on fixed effects. 
Table 2. Fixed and random effects and conditional modes for log counts of international and national articles for 12 psychology journals.

\begin{tabular}{|c|c|c|c|c|c|c|}
\hline & \multicolumn{6}{|c|}{ linear mixed-effects model estimates } \\
\hline & \multicolumn{3}{|c|}{ national articles } & \multicolumn{3}{|c|}{ diff for international articles } \\
\hline & $\begin{array}{l}\text { interc. } \\
\text { (1990) }\end{array}$ & $\begin{array}{l}\text { linear } \\
\text { '75-'07 }\end{array}$ & $\begin{array}{c}\text { quad } \\
\text { '75-`07 }\end{array}$ & intern. & $\begin{array}{l}\text { linear } \\
\text { '75-`07 }\end{array}$ & $\begin{array}{l}\text { quad } \\
\text { '75-‘07 }\end{array}$ \\
\hline \multicolumn{7}{|l|}{ Fixed effects } \\
\hline Estimate & 1.73 & 0.60 & 0.37 & -0.90 & 7.14 & 0.66 \\
\hline SE of estimate & 0.07 & 0.77 & 0.41 & 0.03 & 0.55 & 0.43 \\
\hline t-value (i.e. Est/SE) & 25.78 & 0.78 & 0.92 & -31.04 & 12.98 & 1.53 \\
\hline Random effects (SD) & 0.23 & 2.54 & 1.22 & 0.09 & 1.62 & 1.11 \\
\hline \multicolumn{7}{|c|}{ Journal conditional modes } \\
\hline Psychophysiology & 1.83 & -0.50 & 0.24 & -0.82 & 8.37 & 0.11 \\
\hline Biol Psychol & 1.54 & 1.77 & 1.73 & -0.92 & 4.84 & 2.29 \\
\hline Dev Psychol & 1.92 & -0.80 & -1.11 & -0.97 & 8.64 & -0.35 \\
\hline Psychol Aging & 1.74 & -0.12 & 0.28 & -0.98 & 6.41 & 1.39 \\
\hline J Pers Soc Psychol & 2.20 & -2.30 & -0.77 & -0.99 & 9.69 & -0.16 \\
\hline J Exp Psychol Human & 1.82 & 1.19 & -0.37 & -0.80 & 9.18 & -1.20 \\
\hline J Exp Psychol Learn & 1.85 & 1.02 & -0.12 & -0.93 & 8.02 & -0.10 \\
\hline J Exp Psychol Gen & 1.38 & 0.57 & 0.16 & -0.79 & 6.09 & 0.77 \\
\hline Psychol Bull & 1.70 & -3.66 & -0.61 & -0.99 & 6.31 & 1.99 \\
\hline Psychol Rev & 1.41 & 0.72 & 0.44 & -0.74 & 6.49 & 0.58 \\
\hline Psychon B Rev & 1.62 & 5.47 & 2.80 & -0.91 & 5.06 & 1.69 \\
\hline Psychol Sci & 1.78 & 3.86 & 1.83 & -0.91 & 6.54 & 0.89 \\
\hline
\end{tabular}

Note. $\mathrm{N}$ of cells: $700, \log \operatorname{Lik}=309$, deviance $=-627 ;$ REML deviance $=-618 ;$ resid $\mathrm{SD}=0.14$ 


\section{FIGURE CAPTIONS}

Figure 1. Percentage of articles per year (1975-2007) with authors from different countries (international articles), pooling articles from 12 psychology journals (see Figure 2). Percentage of international articles grows at a constant rate of $7 \%$.

Figure 2. Percentage of international articles per year (1975-2007), separately for 12 psychology journals.

Figure 3. Log number of international articles (bottom line) in comparison to the log number of national articles (top line) from 1975 to 2007, pooling articles from 12 psychology journals (see Figure 4).

Figure 4. Log number of international articles (bottom lines) in comparison to the log number of national articles (top lines) from 1975 to 2007, separately for 12 psychology journals.

Figure 5. Log number of national (left panel) and international articles (right panel) with 1, 2, 3, or a minimum of 4 authors per year (1975-2007). Single-author articles are by defintion national articles; they decrease across the historical period. The growth of international articles is visible irrespective of the number of authors with larger and more similar growth rates than corresponding graphs for national articles. 


\section{FIGURE 1}

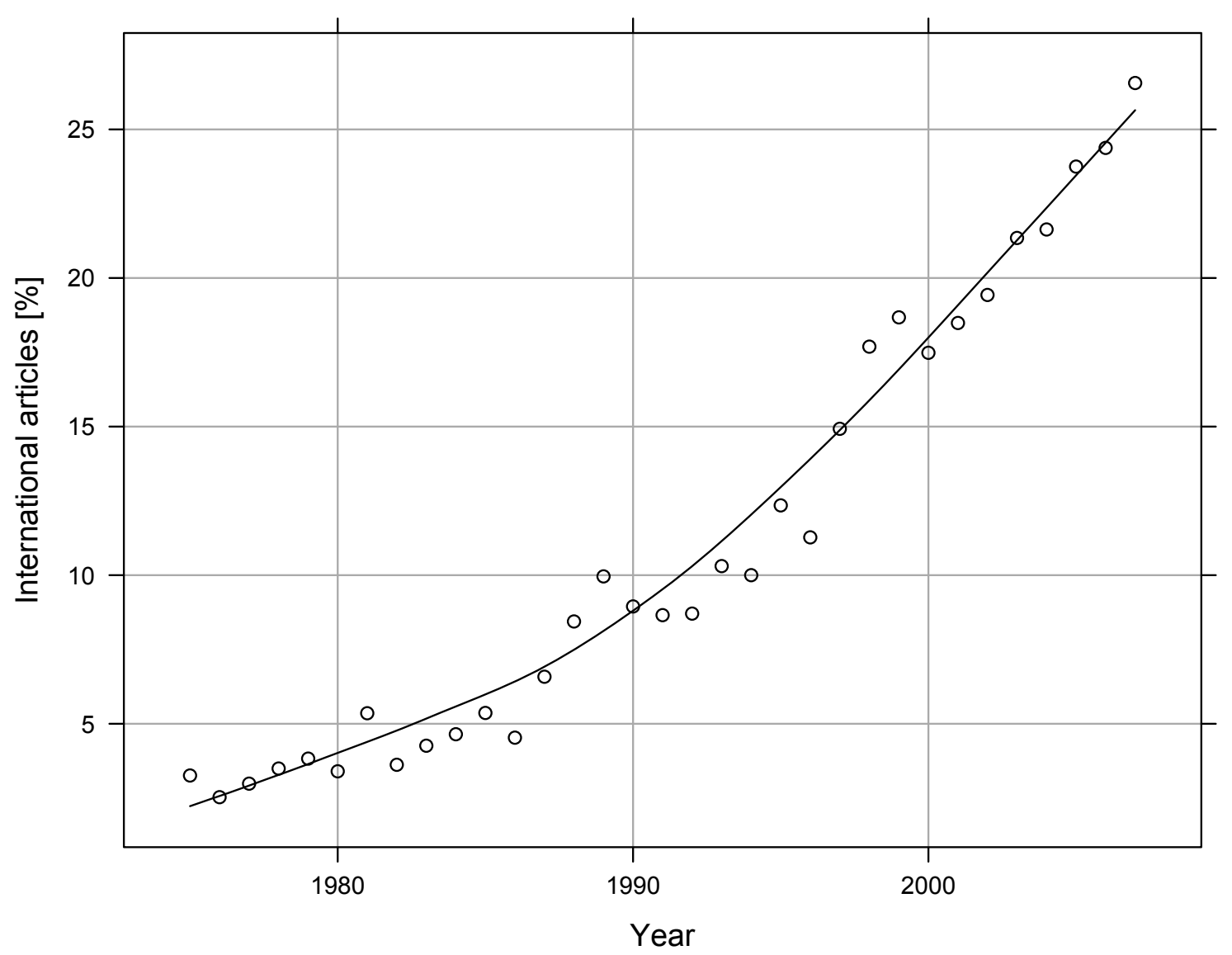


FIGURE 2

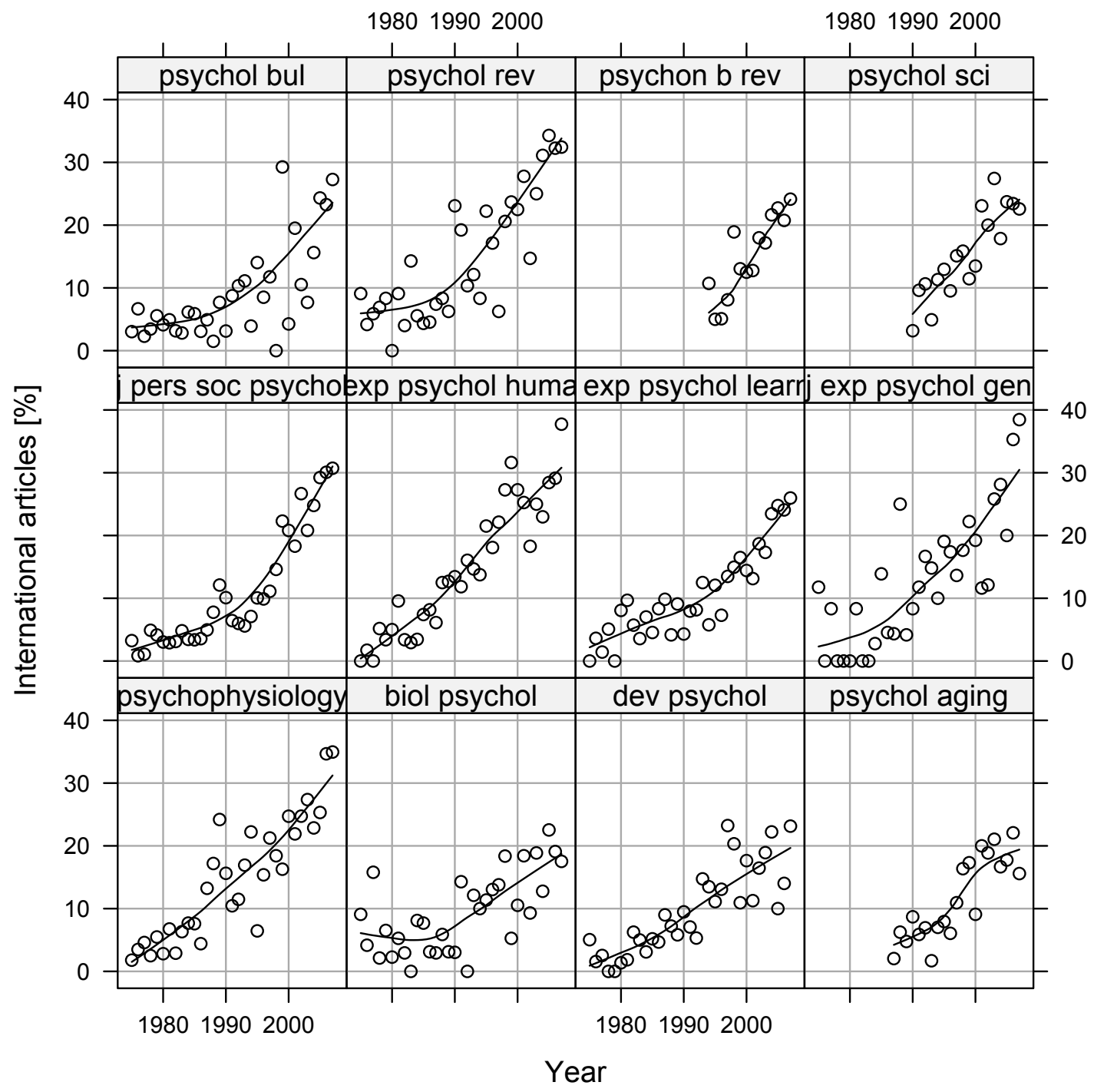




\section{FIGURE 3}

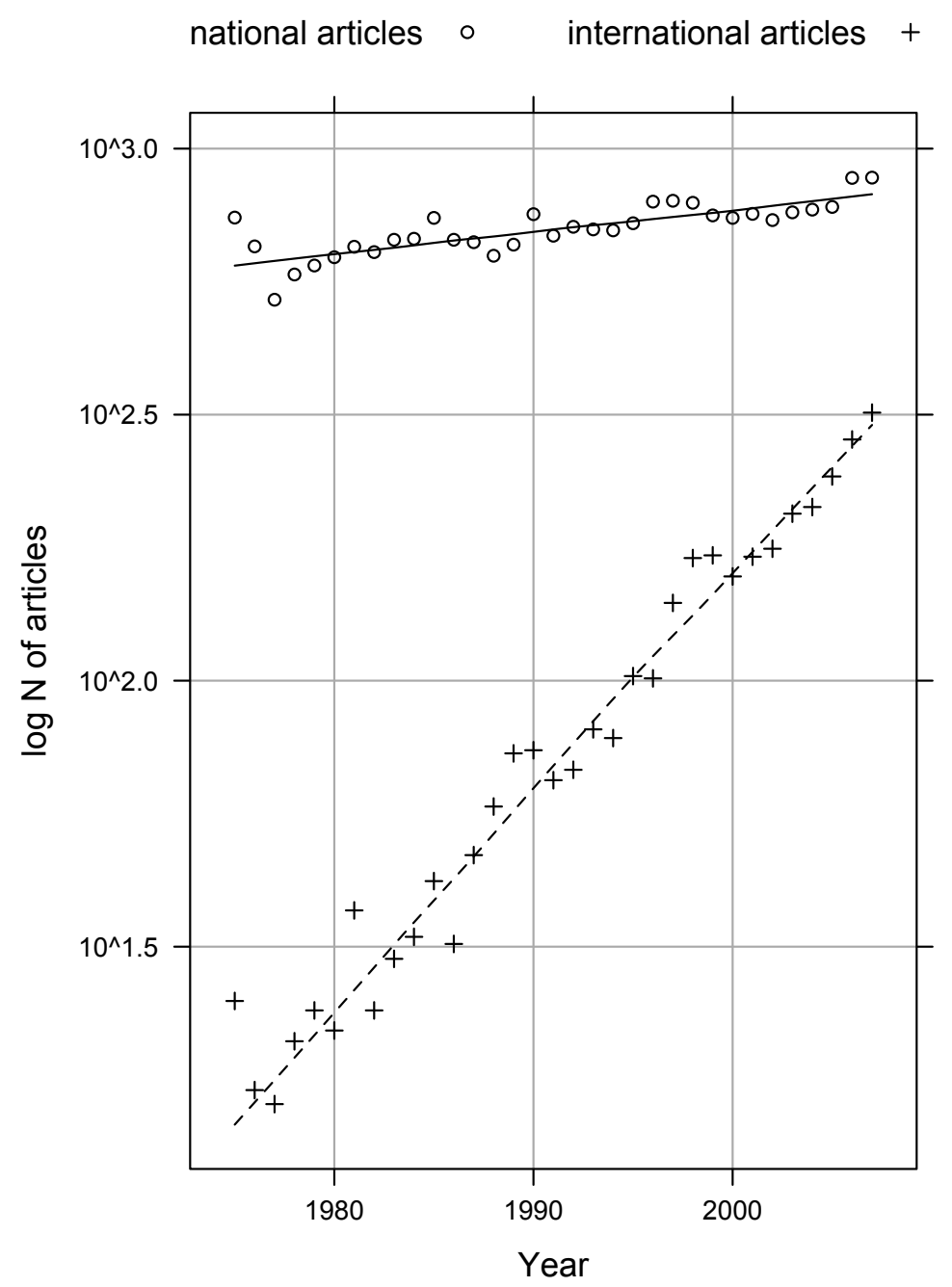


FIGURE 4

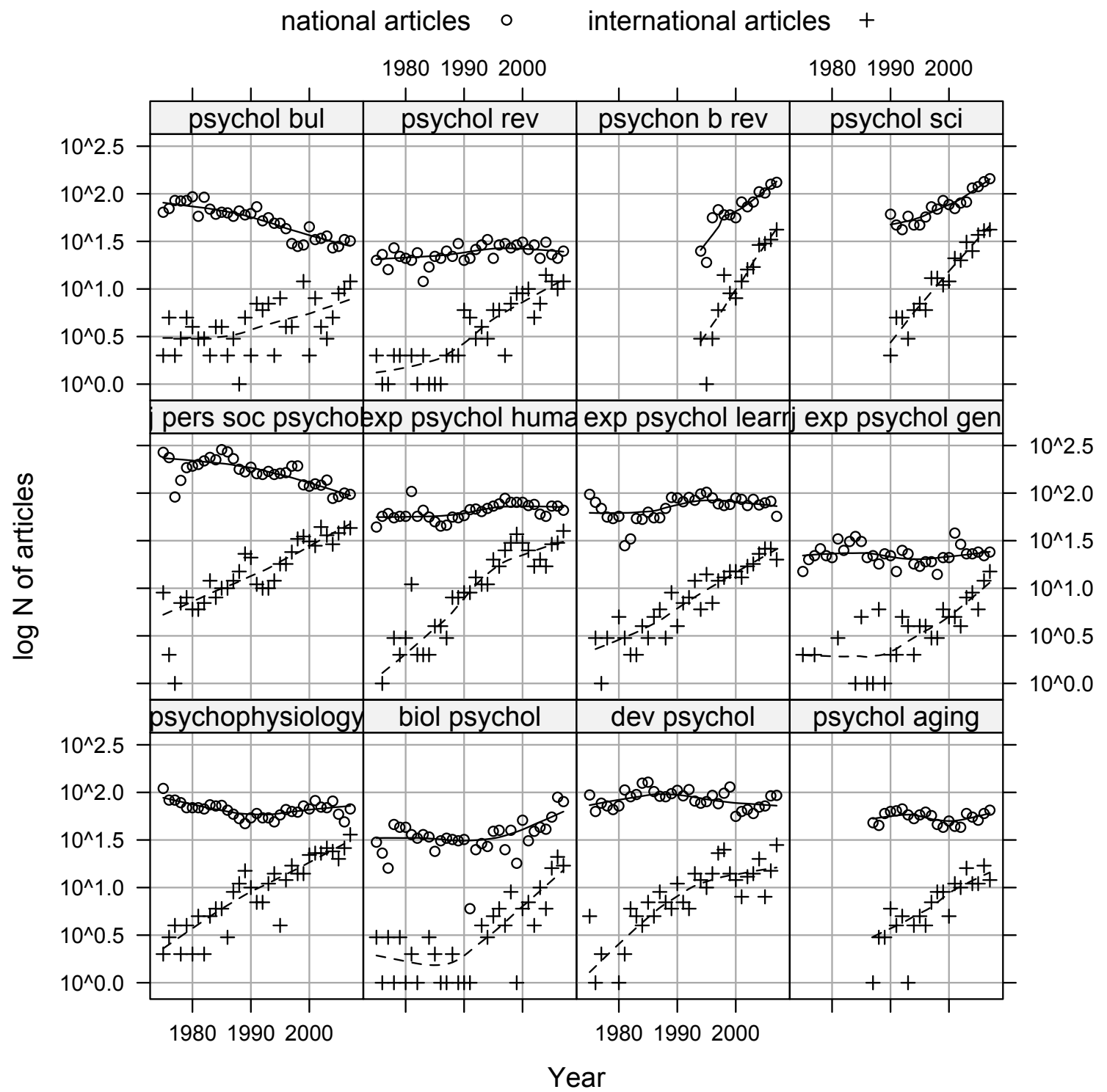


FIGURE 5

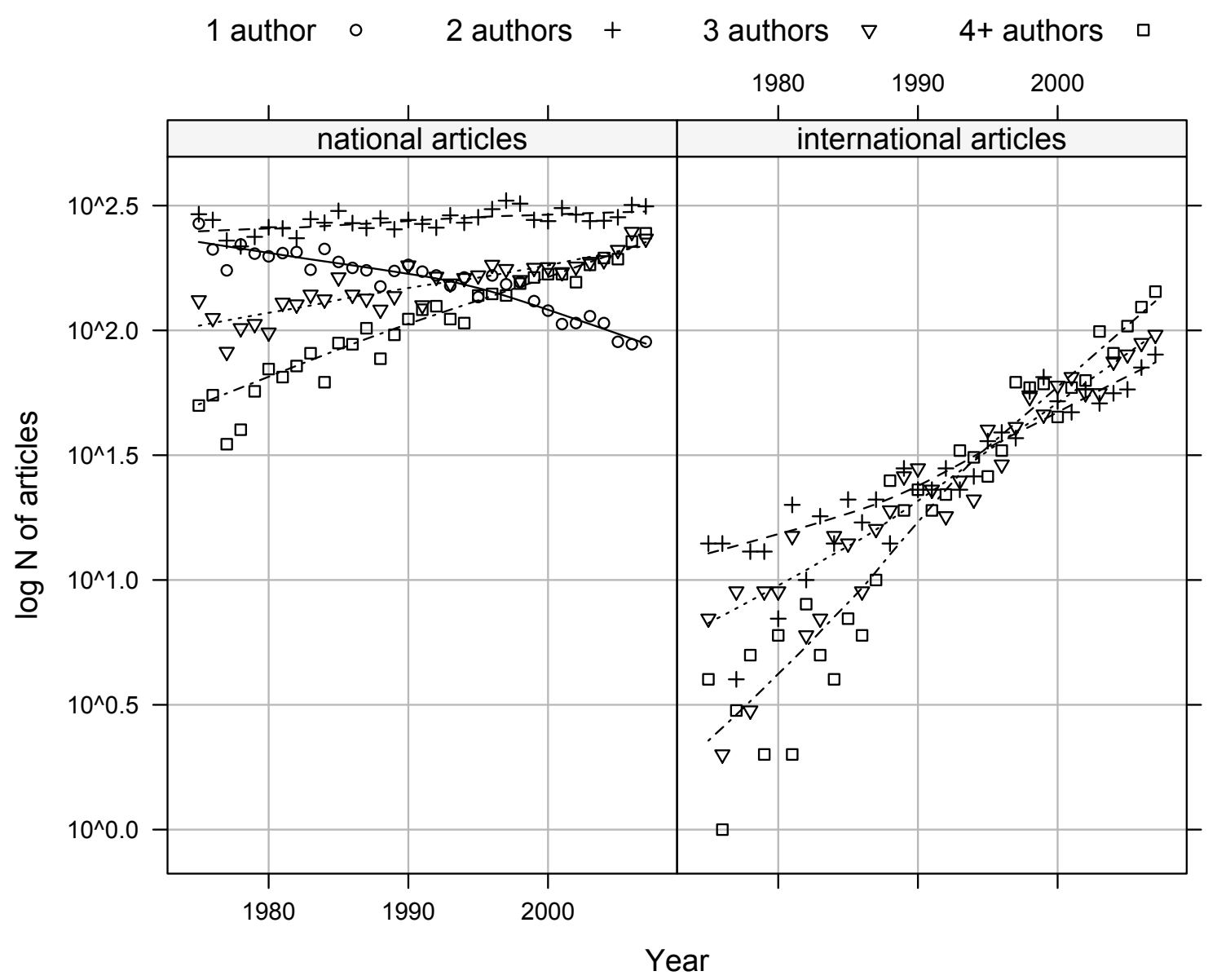

